\title{
Ultrasensitive estrogen levels at 7 years of age predict earlier thelarche: evidence from girls of the growth and obesity Chilean cohort
}

\author{
Ana Pereira ${ }^{1}$, Camila Corvalán ${ }^{1}$, Ricardo Uauy ${ }^{1,2}$, Karen 0 Klein ${ }^{3}$ and \\ Verónica Mericq ${ }^{4}$ \\ ${ }^{1}$ Institute of Nutrition and Food Technology, University of Chile, Avenida El Líbano 5524, Macul, Santiago, Chile, \\ ${ }^{2}$ Department of Neonatology, Faculty of Medicine, Catholic University of Chile, Santiago, Chile, ${ }^{3}$ Department of \\ Pediatrics, University of California, San Diego, California, USA and ${ }^{4}$ Institute of Maternal and Child Research, Faculty \\ of Medicine, University of Chile, Santiago, Chile
}

Correspondence should be addressed to C Corvalán Email

ccorvalan@inta.uchile.cl or ccorval@gmail.com

\begin{abstract}
Objective: Prepubertal estradiol equivalents have been inconsistently linked to age at thelarche; elucidating this relationship becomes relevant given the worldwide decline in the age of puberty onset. Thus, our aim is to assess whether prepubertal girls with higher serum levels of estradiol equivalents at age 7 have a greater risk of presenting early thelarche (ET). Design: Nested case-control study within the Growth and Obesity Cohort Study of 1196 low-middle income children ( $~ 50 \%$ girls) from Santiago, Chile. Girls were defined as cases (ET; $n=61$ ) if breast bud appeared prior to 8 years of age; controls $(n=91)$ had thelarche $>8$ years.

Methods: At 6.7 years, weight, height and waist circumference were measured and a fasting blood sample was obtained for measuring estrogen equivalent (ultrasensitive recombinant cell bioassay), DHEAS, leptin, insulin and IGF1. Beginning at 7 years old, Tanner staging was assessed prospectively twice a year and the appearance of breast bud was assessed by palpation.

Results: Mean serum estradiol-equivalent at 6.7 years was $3.9 \pm 3.6 \mathrm{pg} / \mathrm{ml}$ for cases and $3.6 \pm 2.3 \mathrm{pg} / \mathrm{ml}$ for controls. Girls with ET had a higher risk of presenting elevated estradiol-equivalent ( $\geq 5 \mathrm{pg} / \mathrm{ml}$ ) at 7 years $(\mathrm{OR}=2.05,95 \% \mathrm{Cl}: 0.96-4.36)$ than controls that was borderline significant. However, after adjusting by BMI, insulin and IGF1 at age 7, the association between estradiol-equivalent and ET was significant (OR=2.29 (95\% Cl: 1.05-5.01)).

Conclusions: Chilean girls from low to middle socioeconomic status with ET exhibited double the risk of having high levels of estradiol-equivalent at 7 years than girls with a later age of thelarche. Whole-body adiposity and increased adrenal activity did not explain the observed prepubertal estrogen increase.
\end{abstract}

\section{Introduction}

American and European studies have suggested a secular decline in the age of puberty onset in girls of about 1 year during the past 15-20 years (1). Pubertal timing is strongly determined by genetic factors (2), but genotype alone cannot explain this rapid decline due to the short time frame. Alternatively, obesity, fetal and childhood nutrition, dietary habits, physical activity and endocrine disruptor chemicals might account for this trend (1).
Age at puberty onset has been associated with future health, with an earlier age of thelarche linked to increased breast cancer risk, diabetes and other adult chronic diseases (3).

Breast development occurs as the result of either increased breast sensitivity to estrogen or to a permanent or transient rise in plasma estrogen (4). Higher circulating estradiol concentrations have been demonstrated in a

Published by Bioscientifica Ltd. 
cross-sectional study of girls with premature thelarche (5). A longitudinal study in girls revealed that urinary estrogen levels 1 or 2 years prior to the pubertal growth spurt predicted earlier thelarche and menarche ( 0.9 and 0.3 years respectively) (6). Additionally, insulin and insulinlike growth factor 1 (IGF1) could also modify breast development by promoting breast cell division as it has been observed in adults $(7,8,9)$.

The increase in estrogen can be the result of physiological GnRH axis activation $(10,11)$. However, estrogen can also increase due to transient estradiol secretion by ovarian cysts or increased production of adrenal precursors or dietary estrogen, among other factors. Environmental chemicals with estrogen activity, the so-called endocrine disruptors, may accelerate the onset of thelarche, even triggering the central initiation of puberty (12). Obesity in particular has been proposed to increase circulating estrogen levels by several pathways. First, obesity may trigger central gonadotropin secretion by increasing leptin levels that play a permissive role in gonadotropin secretion (13). Another possibility is that insulin resistance increases adrenal androgen concentration in blood $(14,15)$, which in combination with insulin and leptin may further facilitate GnRH pulsatile secretion and thus increase androgen synthesis by ovarian theca cells (16). Alternatively, circulating sex steroid hormones can be higher in obese children due to increased aromatase activity, leading to peripheral conversion of androgens to estrone and estradiol (11). In addition, lower concentrations of sex hormone binding globulin (SHBG) secondary to insulin resistance may further increase estrogen activity (17).

Thus our aim was to assess whether low levels of prepubertal estrogen at age 7 are associated with earlier thelarche in subjects who did not develop thelarche at age 7 , in a cohort of low- to middle-income Chilean girls followed up since birth, and to assess whether this is explained by increased adiposity considering other relevant metabolic and hormonal factors as potential covariates.

\section{Subjects and methods}

\section{Growth and Obesity Chilean Cohort Study}

We conducted a nested case-control study within the Growth and Obesity Chilean Cohort Study (GOCS). In GOCS, 1196 children ( 49\% girls) were enrolled in 2006 from public child-care centers of the South East area of Santiago, Chile. Participants were singleton births during 2002-2003, who had birth weights between 2500 and
$4500 \mathrm{~g}$, with no medical or mental conditions. All girls with medical conditions or diagnosed with precocious puberty during follow-up were excluded $(n=2)$. Since 2006 (mean age 4 years), we collected longitudinal data on anthropometric measures, skeletal maturation, metabolic and hormonal markers and semiannual Tanner assessments (every 6 months) (18). More details of the study protocol have been published elsewhere (19). For the present study, cases were identified based on the presence of early thelarche (ET), defined as the appearance of a 'breast bud' below the areola (palpable subareolar bud; Tanner B2) (20) prior to 8 years. From a total of 104 girls with ET, we randomly selected 90 girls based on sample size calculation for the present analyses. From these 90 girls, we excluded 23 girls who were already Tanner B2 at the time of blood sampling (mean estradiol equivalents of 7.5, S.D. $=8.5 \mathrm{pg} / \mathrm{ml}$ ) where the blood sample therefore could not be considered prepubertal. Five girls were also excluded due to regression of B2 during follow-up, and they were classified as transient thelarche. Finally, we ended up with 62 cases. We randomly selected 90 controls from 442 girls that presented thelarche at 8 years of age or after; considering the five cases reassessed as controls (in those subjects with transient thelarche, mean estradiol equivalents did not differ from the other controls), we ended up with 95 controls. We further excluded two girls (one case and one control) whose plasma level of estradiolequivalents exceeded 5 s.D. of the sample mean (outliers); thus, the final sample size for the study was 61 cases and 94 controls. In all cases and controls, we measured estradiolequivalents in blood extracted at 7 years of age (cases $=6.7$ years (s.D. $=0.5$ ) and at 6.7 years of age in controls $($ s.D. $=0.4)$ ); in cases, the blood extraction was 8.5 months prior to the $\mathrm{B} 2$ onset (s.D. $=4.7$ ) and in controls it was 35.7 months before (s.D. $=9.1$ ).

\section{Data collection and assays}

Anthropometric measures $>$ Annually trained dietitians obtained anthropometric measurements in all girls (barefoot and in light clothes) using standardized protocols (intra-class correlation for all measurements $\geq 0.75$ ) $(19,21)$. Weight was measured with a portable electronic measurement scale (Seca 770, Seca Latda, Hamburg, Germany), precision of $0.1 \mathrm{~kg}$, and height was measured with a portable stadiometer (Harpenden 603; Holtain LTD, Crosswell, UK) to the nearest $0.1 \mathrm{~cm}$. Waist circumference was measured just above the iliac crest, with the subject standing, using a Seca tape measure, in centimeters $(0.1 \mathrm{~cm})$. 
Tanner assessment $>$ Starting in 2009 (mean age of girls 6.7 years), one female nutritionist trained by a pediatric endocrinologist (intra- and inter-rater variability of 0.9 ) assessed breast bud appearance by palpation. Assessments were repeated every 6 months at the outpatient clinic of the Institute of Nutrition and Food Technology (INTA). All doubtful cases were evaluated by a pediatric endocrinologist (V M). Age at thelarche was estimated as the midpoint age between the last visit without breast bud and the first visit in which the breast bud was detected.

Ultrasensitive estrogen $\bullet$ During 2009 (mean age 6.7 years S.D. $=0.4)$, we obtained a fasting $(8 \mathrm{~h})$ blood sample that was immediately centrifuged and stored at $-20^{\circ} \mathrm{C}$. Ultrasensitive estrogen determinations were carried out in these samples by Oerter Klein at the University of California, San Diego, USA using a validated technique (22). The ultrasensitive assay is a recombinant cell bioassay (RCBA) technique using a strain of Saccharomyces cerevisiae transformed with two plasmids. One plasmid contains the human estrogen receptor complementary DNA and the other plasmid includes an estrogen response element upstream from the structural gene for $\beta$-galactosidase (23). The sensitivity of the bioassay is $0.02-$ $0.2 \mathrm{pg} / \mathrm{ml}(0.07-0.7 \mathrm{pmol} / \mathrm{l})$; the intra-assay and interassay coefficients of variation $(\mathrm{CV})$ at $0.2 \mathrm{pg} / \mathrm{ml}$ (0.7 pmol/l) ranged from $10 \%$ to $50 \%(24)$.

Other hormonal and metabolic markers $>$ Plasma extracted in 2009 served to determine: i) DHEAS by ELISA using commercial kits (Diagnostic Product, Inc., Cypress, TX, USA; sensitivity 10 pg/ml; intra- and inter-CV assay $4 \%$ and $8 \%$ respectively) ii) insulin by RIA (sensitivity $0.5 \mathrm{mUI} / \mathrm{ml}$, intra- and inter-CV assay $8.6 \%$ and $10.2 \%$ respectively); iii) IGF1 by RIA (sensitivity $5 \mathrm{ng} / \mathrm{ml}$, intra- and inter-CV assay $8.6 \%$ and $10.2 \%$ respectively); and iv) leptin by IRMA (sensitivity 0 , $10 \mathrm{ng} / \mathrm{ml}$, intra- and inter-CV assay $4.6 \%$ and $6.2 \%$ respectively).

Maternal information - Mothers provided information about their own age at menarche at the time of the outpatient visit for blood extraction (year 2009).

\section{Computed indices}

BMI was calculated as weight (kg)/height (m) (2). Anthropometric $\mathrm{Z}$ scores were estimated using the World Health Organization 2007 reference (25). BMI was categorized as underweight (BMI $Z$-score $<-1$ s.D.), normal (BMI $Z$-score -1 s.D. to +1 s.D.) and overweight/ obese (BMI $Z$-score $>1$ s.D.) (25). Waist circumference was dichotomized in the $75 \mathrm{th}$ percentile $(63.0 \mathrm{~cm}$ for age 7.0-7.9) of the Mexican-American girls reference of the Third National Health and Nutrition Examination Survey (NHANES III) (26). Estradiol-equivalent level at age 6.7 (s.D. $=0.4$ ) was dichotomized in 5 or more $\mathrm{pg} / \mathrm{ml}$ and $<5 \mathrm{pg} / \mathrm{ml}$ (75th percentile of the sample distribution).

\section{Statistical analysis}

Sample size and power calculations were based on a final sample size of 61 cases and 94 controls, test significance level of 0.05 and one-sided test. We estimated three different scenarios of the study power according to three different ORs (2.0, 2.2 and 2.6) for the association between estrogen levels and ET were $\beta=50,60$ and 76 , respectively.

Descriptive analysis (mean, s.D., median and percentile) of estradiol equivalents and the other variables (confounders) were computed. Crude OR and 95\% CI to assess relationships between estradiol equivalents at age 6.7 (dichotomic variable) and ET were estimated using logistic regression models. In order to determine the role of adiposity and metabolic and hormonal variables as potential explanatory or confounder variables, we adapted the conceptual causal diagram proposed by Burt Solorzano \& McCartney (16) (Fig. 1) to describe the potential pathways that link adipose tissue and its related metabolic and hormonal factors with increased estrogen concentrations and breast tissue growth. Based on this model, we evaluated in the control group the associations and interactions between adiposity, metabolic and hormonal data and plasma levels of estradiol equivalents. Furthermore, given the complexity of the relationships among predictors, causal relationships were assessed using direct acyclic graph (DAG) as shown in Fig. 1. DAG is used in epidemiology to assess causal diagrams, aimed at identifying potential confounders and other sources of bias, based on scientific knowledge rather than statistical criteria (27). As shown in Fig. 1, we propose two alternative models to assess the relationship of estrogen and thelarche, accounting for potential confounders and avoiding overadjustment: Model 1 includes adjusting by obesity, insulin and IGF1 at age 6.7. Model 2 includes adjusting by DHEAS and insulin at age 6.7 ; both models were also adjusted by maternal age at menarche. These two models should give comparable results.

We further carried out two sensitivity analysis. First, we excluded girls who regressed from Tanner B2 to Tanner 


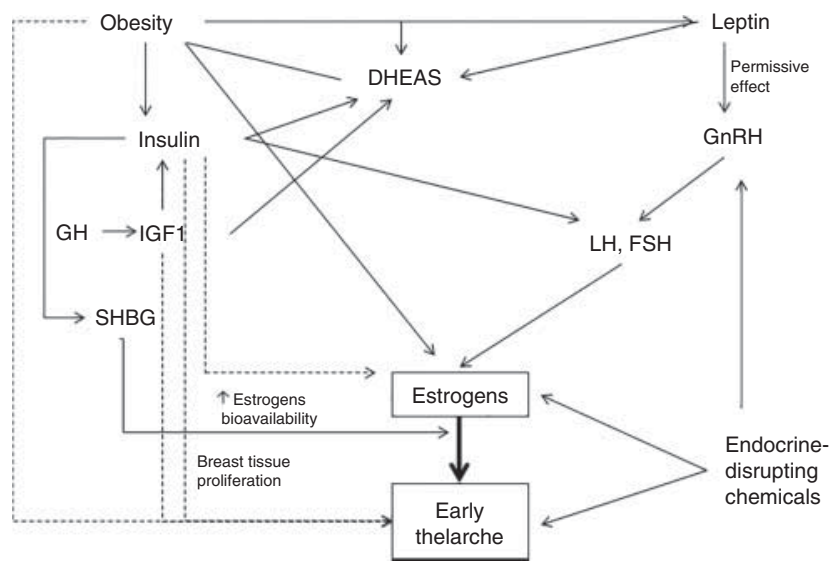

Figure 1

Direct acyclic graph: potential confounders and backdoor pathways between estrogen levels during prepuberty and ET onset. Endogenous estrogen can be the result of the GnRH axis activation as it happens in normal pubertal onset. Obesity increases leptin levels, which have a permissive role on gonadotropin secretion (13). Also, circulating sex steroid hormones are increased by peripheral conversion at the adipose tissue of androgens to estrone and estradiol, by the adipose aromatase (11) and reduction of sex hormone-binding globulin secondary to insulin resistance (17). Furthermore, insulin resistance increases the levels of hyperandrogenemia (14), which in combination may facilitate the GnRH pulsatile secretion and increase pituitary secretion (37) and androgen secretion at the ovarian theca cells (16). Additionally, in adults, insulin and IGF1 stimulate breast cell division $(7,8)$; thus, they could be involved in breast development in early puberty (9). Endocrine disruptors that mimic estrogen functions may accelerate age at thelarche onset (16), even triggering central initiation of puberty (12).

B1 in two consecutive measurements $(n=5)$. Secondly, we replaced adiposity measurements at 7 years by those at 5 years in order to have a longer time period between obesity and the increase of estrogen levels, hypothesizing that the effect of obesity on estrogen levels would need a more permanent exposure.

\section{Ethics}

GOCS has been approved by INTAs Ethic Board Committee and that meet USA ORP/NIH standards. All parents or tutors signed an informed consent form and all girls assented to participate prior to entry in the study.

\section{Results}

In 2009 (time at estrogen levels measurement), the mean age of participants was 6.7 years (s.D. 0.5 for cases and 0.4 for controls) and mean serum estradiol-equivalents was $3.9 \mathrm{pg} / \mathrm{ml}$ (S.D. =3.6) for cases and 3.6 (S.D.=2.3) for controls (Fig. 2).

As shown in Table 1, the mean age of thelarche in cases was $7.4 \pm 0.4$ years and in controls $9.7 \pm 0.8$ years. Girls with ET had twofold higher levels of serum estradiol equivalents higher than $5 \mathrm{pg} / \mathrm{ml}$ (sample 75 th percentile) than controls; however, this difference was not significant $(P=0.06)$. ET girls were taller than their counterparts and had significantly higher levels of DHEAS at age $7(P<0.05)$ but did not differ in adiposity or other metabolic or hormonal measurements $(P>0.05)$; maternal age at menarche was also similar for cases and controls.

The univariate analysis (Table 2) revealed that girls with earlier thelarche had twice the probability of having higher levels of prepubertal estradiol equivalents than controls ( $\mathrm{OR}=2.05$, 95\% CI: 0.96-4.36); however, this was not significant. After adjusting for potential confounders, the effect became stronger and significant if adjusted for BMI, insulin and IGF1 at age 7 (Model 1: OR $=2.29$; 95\% CI: 1.05-5.01). After adjusting by DHEAS and insulin, the directionality and strength remained similar but was not significant. Similar results were observed after adjusting for mother's age at menarche. Our sensitivity analysis, excluding girls with transient thelarche, showed similar
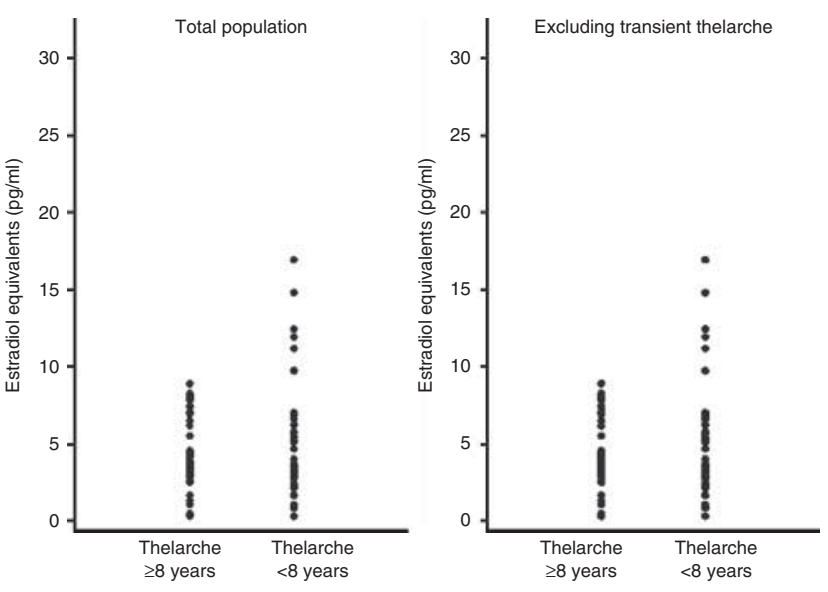

Figure 2

Ultrasensitive estrogen distribution in cases (thelarche $<8$ years) and controls (thelarche $\geq 8$ years) in the entire study population sample and excluding those with transient thelarche. 
Table 1 Distribution of estradiol-equivalents, adiposity, height, metabolic, hormonal data and mother's age at menarche in cases (thelarche $<8$ years) and controls (thelarche $>8$ years). Data are presented as mean \pm s.D. or as $n(\%)$.

\begin{tabular}{|c|c|c|c|}
\hline & \multicolumn{2}{|c|}{ Thelarche } & \multirow[b]{2}{*}{$P$ value } \\
\hline & $<8.0$ years $(n=61)$ & $\geq 8.0$ years $(n=94)$ & \\
\hline $\begin{array}{l}\text { Age at blood } \\
\text { extraction }^{a}\end{array}$ & $6.7 \pm 0.5(5.7-7.6)$ & $6.7 \pm 0.4(5.7-7.4)$ & 0.724 \\
\hline $\begin{array}{l}\text { Age at thelarche } \\
\text { onset }^{a}\end{array}$ & $7.4 \pm 0.4(6.4-7.9)$ & $9.7 \pm 0.8(8.2-11.3)$ & \\
\hline \multicolumn{4}{|c|}{ Estradiol equivalents (pg/ml) } \\
\hline$<5$ & $42(68.85 \%)$ & $77(81.91 \%)$ & 0.06 \\
\hline$\geq 5$ & $19(31.15 \%)$ & $17(18.09 \%)$ & \\
\hline \multicolumn{4}{|c|}{ Anthropometric measures } \\
\hline $\begin{array}{l}\text { Birthweight in } \\
\text { grams }\end{array}$ & $3392 \pm 53.00$ & $3310 \pm 41$ & 0.214 \\
\hline \multicolumn{4}{|l|}{ BMI at 7 years } \\
\hline z-score & $0.80 \pm 0.89$ & $0.89 \pm 1.06$ & 0.589 \\
\hline $\begin{array}{l}\text { Underweight } \\
(<-1 \text { s.D. })\end{array}$ & $0(0.00 \%)$ & $2(2.13 \%)$ & 0.662 \\
\hline $\begin{array}{l}\text { Normal } \\
\text { ( }-1 \text { S.D. to } 1 \text { s.D. })\end{array}$ & $36(59.02 \%)$ & $56(59.57 \%)$ & \\
\hline $\begin{array}{l}\text { Overweight }+ \\
(>+1 \text { s.D. })\end{array}$ & $25(40.98 \%)$ & $36(38.30 \%)$ & \\
\hline \multicolumn{4}{|c|}{ Waist circumference at 7 years $(p 75)$} \\
\hline$<63.00 \mathrm{~cm}$ & $47(81.03 \%)$ & $71(78.02 \%)$ & 0.686 \\
\hline$\geq 63.00 \mathrm{~cm}$ & $11(18.97 \%)$ & $20(21.98 \%)$ & \\
\hline \multicolumn{4}{|c|}{ Height for age $z$-score } \\
\hline \multicolumn{4}{|c|}{ Height for age at 7 years } \\
\hline$<-1$ S.D. & $4(6.56 \%)$ & $12(12.77 \%)$ & 0.001 \\
\hline-1 S.D. to 1 S.D. & $37(60.66 \%)$ & $73(77.66 \%)$ & \\
\hline+1 S.D. & $20(32.79 \%)$ & $9(9.57 \%)$ & \\
\hline \multicolumn{4}{|c|}{ Metabolic and hormonal data } \\
\hline Insulin $(\mu \mathrm{lU} / \mathrm{ml})$ & $5.7 \pm 0.30$ & $5.8 \pm 0.20$ & 0.937 \\
\hline IGF1 (ng/ml) & $190.8 \pm 5.40$ & $181.9 \pm 4.00$ & 0.184 \\
\hline Leptin $(\mu \mathrm{g} / \mathrm{ml})$ & $5.23 \pm 0.41$ & $5.84 \pm 0.40$ & 0.306 \\
\hline DHEAS $(p g / m l)$ & $389.7 \pm 28.00$ & $310.4 \pm 15.10$ & 0.008 \\
\hline \multicolumn{4}{|c|}{ Mother's age of menarche } \\
\hline$<11$ years & $5(9.26 \%)$ & $4(5.56 \%)$ & 0.737 \\
\hline $11-13$ years & $34(62.96 \%)$ & $48(66.67 \%)$ & \\
\hline$>13$ years & $15(27.78 \%)$ & $20(27.78 \%)$ & \\
\hline
\end{tabular}

${ }^{a}$ Value in brackets represents range.

results; girls with ET had twice the risk of having higher levels of estrogen, but it was borderline significant $\left(\mathrm{OR}_{\text {(adj:Model 1) }}=2.07 ; 95 \%\right.$ CI: 0.94-4.59; $\mathrm{OR}_{(\text {adj:Model 2) }}=$ 1.94; 95\% CI: 0.87-4.29) (data not shown in the table). We repeated the analyses, replacing adiposity at 7 years by measurements at 5 years; results remained the same (data not shown). Also, we have done analyses considering means of estradiol equivalents and the results confirm the associations (data not shown).

Finally, in order to assess the role of the covariates, we evaluated their relationship with estradiol equivalent levels in the control group. No relationships between covariates (adiposity, hormonal, metabolic and mother's age at menarche) and estradiol equivalents $(<5 \mathrm{pg} / \mathrm{ml}$ vs $\geq 5 \mathrm{pg} / \mathrm{ml}$ ) were observed (Table 3). All interactions tested were non-significant $(P>0.05)$.

\section{Discussion}

In our study, we observed that girls with ET ( $<8$ years) have twice the risk of having estradiol equivalents of $5 \mathrm{pg} / \mathrm{ml}$ or more at 6.7 years, after adjusting for potential confounders, compared to girls who have later thelarche. Thus, in this sample of low- to middle-income Chilean girls, estrogen levels at mean age 6.7 (prepubertal) were positively associated with an earlier thelarche. Moreover, our results suggest that the relation between estrogen levels at mean age 6.7 years and earlier thelarche is not explained by increased adiposity and/or accelerated maturation of the adrenal axis.

Evidence regarding the role of estrogen on pubertal onset is scarce because assessing prepubertal estrogen concentrations requires special bio-assays capable of detecting low estrogen concentrations. Our results are in line with published work $(5,24,28)$. Janfaza et al. (24) carried out a study of 375 girls (age 4.4-18 years) in whom estradiol-equivalents were measured using the same method as Klein et al. (22), demonstrating that estrogen increased with age and pubertal stage. Additionally, a recent cross-sectional report of 627 American girls (white, black and Hispanics) (mean age $=12$ years and S.D. $=3.0$ ) showed that higher estrogen levels and body fat were independently associated with breast development (B2 or more); however, measures of estrogen and body fat were concurrent to Tanner breast staging and they were not able to report on the effect of prepubertal estrogen (28).

Table 2 Crude and adjusted odds ratios and $95 \% \mathrm{Cl}$ of estradiol-equivalents between cases (thelarche $<8$ years) and controls (thelarche $\geq 8$ years).

\begin{tabular}{|c|c|c|c|}
\hline Models & OR & $95 \% \mathrm{Cl}$ & $P$ value \\
\hline Crude & 2.05 & $0.96 ; 4.36$ & 0.062 \\
\hline \multicolumn{4}{|l|}{ Adjusted by } \\
\hline BMI + insulin at 7 years old & 2.05 & $0.96 ; 4.38$ & 0.065 \\
\hline $\mathrm{BMI}+$ insulin + IGF1 at 7 years old & 2.29 & $1.05 ; 5.01$ & 0.037 \\
\hline DHEAS + insulin at 7 years old & 2.11 & $0.97 ; 4.60$ & 0.059 \\
\hline $\begin{array}{l}\text { BMI+ insulin at } 7 \text { years old }+ \\
\text { mother's age at menarche }\end{array}$ & 2.05 & $0.90 ; 4.66$ & 0.087 \\
\hline $\begin{array}{l}\text { BMI + insulin + IGF1 at } 7 \text { years } \\
\text { old + mother's age at menarche }\end{array}$ & 2.26 & $0.97 ; 5.26$ & 0.059 \\
\hline $\begin{array}{l}\text { DHEAS + Insulin at } 7 \text { years old + } \\
\text { mother's age at menarche }\end{array}$ & 2.13 & $0.93 ; 4.92$ & 0.075 \\
\hline
\end{tabular}


Table 3 Distribution of adiposity, height, metabolic, and hormonal data according to estradiol equivalents levels ( $<5 \mathrm{pg} / \mathrm{ml}$ vs $\geq 5 \mathrm{pg} / \mathrm{ml}$ ) in girls whose age of thelarche was $\geq 8$ years. Data are presented as mean \pm s.D. or $n(\%)$.

\begin{tabular}{|c|c|c|c|}
\hline \multirow[b]{2}{*}{ Variables } & \multicolumn{2}{|c|}{ Estradiol equivalents } & \multirow[b]{2}{*}{$P$ value } \\
\hline & $\begin{array}{c}<5 \mathrm{pg} / \mathrm{ml} \\
(n=77)\end{array}$ & $\begin{array}{c}\geq 5 \mathrm{pg} / \mathrm{ml} \\
(n=17)\end{array}$ & \\
\hline \multicolumn{4}{|l|}{ Adiposity } \\
\hline \multicolumn{4}{|l|}{ BMl at birth } \\
\hline $\begin{array}{l}\text { Underweight } \\
(<-1 \text { s.D. })\end{array}$ & $16(20.78 \%)$ & $2(11.76 \%)$ & 0.347 \\
\hline $\begin{array}{l}\text { Normal } \\
(-1 \text { S.D to } 1 \text { S.D. })\end{array}$ & $49(63.64 \%)$ & $10(58.82 \%)$ & \\
\hline $\begin{array}{l}\text { Overweight }+ \\
(>+1 \text { s.D. })\end{array}$ & $12(15.58 \%)$ & $5(29.41 \%)$ & \\
\hline \multicolumn{4}{|l|}{ BMI at 7 years } \\
\hline $\begin{array}{l}\text { Underweight } \\
\text { (<- } 1 \text { S.D. })\end{array}$ & $2(2.60 \%)$ & $0(0.00 \%)$ & 0.747 \\
\hline $\begin{array}{l}\text { Normal } \\
\quad(-1 \text { s.D to } 1 \text { S.D. })\end{array}$ & $45(58.44 \%)$ & $11(64.71 \%)$ & \\
\hline $\begin{array}{l}\text { Overweight }+ \\
(>+1 \text { S.D. })\end{array}$ & $30(38.96 \%)$ & $6(35.29 \%)$ & \\
\hline \multicolumn{4}{|c|}{ Waist circumference at 7 years (p75) } \\
\hline$<63.00 \mathrm{~cm}$ & $57(77.03 \%)$ & $14(82.35 \%)$ & 0.633 \\
\hline$\geq 63.00 \mathrm{~cm}$ & $17(22.97 \%)$ & $3(17.65 \%)$ & \\
\hline \multicolumn{4}{|c|}{ Height for age } \\
\hline \multicolumn{4}{|c|}{ Height for age at 7 years } \\
\hline$<-1$ S.D. & $10(12.99 \%)$ & $2(11.76 \%)$ & 0.831 \\
\hline-1 S.D to 1 S.D. & $59(76.62 \%)$ & $14(82.35 \%)$ & \\
\hline+1 S.D. & $8(10.39 \%)$ & $1(5.88 \%)$ & \\
\hline \multicolumn{4}{|c|}{ Metabolic and hormonal data } \\
\hline Insulin $(\mu \mathrm{lU} / \mathrm{ml})$ & $5.86 \pm 0.19$ & $5.3 \pm 0.18$ & 0.187 \\
\hline IGF1 (ng/ml) & $182.76 \pm 4.34$ & $178.19 \pm 10.93$ & 0.666 \\
\hline Leptin $(\mu \mathrm{g} / \mathrm{ml})$ & $5.82 \pm 0.43$ & $5.95 \pm 1.03$ & 0.899 \\
\hline DHEAS $(\mathrm{pg} / \mathrm{ml})$ & $313.69 \pm 17.10$ & $295.35 \pm 31.82$ & 0.643 \\
\hline \multicolumn{4}{|c|}{ Mother's age of menarche (years) } \\
\hline$<11$ & $4(7.02 \%)$ & $0(0.00 \%)$ & 0.373 \\
\hline $11-13$ & $36(63.16 \%)$ & $12(80.00 \%)$ & \\
\hline$>13$ & $17(29.82 \%)$ & $3(20.00 \%)$ & \\
\hline
\end{tabular}

Higher levels of prepubertal estrogen may be reflecting initial activation of the axis. Unfortunately, we did not measure gonadotropin concentration in our subjects to test this hypothesis. Marshall \& Tanner (18) showed that the mean time between B2 and B3 was 0.9 years (s.D. $=0.48$ ); in our cohort, only four girls with ET progressed to B3 within 1 year (data not shown), suggesting ET in this cohort might not be triggered by activation of the hypothalamus-pituitary-gonadal (HPG) axis. The suggestion that secular declines on age at thelarche does not necessarily represent earlier activation of the HPG axis is supported by results of Aksglaede et al. (29), who compared two different cohorts (1991-1993; $n=1100$ vs $2006-2008 ; n=995)$ observing a significant decline on age at attainment of B2 (10.9 vs 9.9 respectively), with no significant differences in estradiol levels, serum follicle-stimulating hormone and luteinizing hormone before 8 years when comparing the two cohorts.

Another potential explanation for the increase in prepubertal estrogen levels observed in girls with ET might be that the levels are elevated as a consequence of increased conversion of androgens by the adipose tissue aromatase. In our cohort of children, we have previously described that at age 7 none of the girls had signs of pubarche; however DHEAS is positively associated to various adiposity markers. Furthermore, obese children with higher DHEAS concentrations had higher total fat and central adiposity than obese children with lower DHEAS concentrations (30). Despite these previous findings, our analyses show that estrogen levels were independent of obesity. This is in line with two reports by Klein et al. $(5,31)$ In girls with premature thelarche before 3 years, estradiol equivalents were not correlated with BMI, weight or height (5). In the second study in a sample of 23 girls at Tanner stage 2 and 25 boys in Tanner stage 1 and 2, they observed no association between estradiol equivalents and BMI (31). Similar findings are reported by Crocker et al. (28), who did not observe an association between body fat and estrogen levels, although they did not use ultrasensitive bioassays (28). Aksglaede et al. (29) also could not explain differences in age at puberty onset because of the obesity increase.

Consistent with these findings, we did not find significant associations between estradiol equivalents and metabolic and hormonal factors related to obesity. Conversely, Klein et al. (31) described a strong association between estradiol equivalents, IGF1 and DHEAS levels. Differences might be due to the higher proportion of obese children $(50 \%)$ of her sample, as all girls were in Tanner breast stage 2, and the fact that her analysis also included boys.

The ultrasensitive estrogen assay may have the potential to measure other estrogen-like substances different from endogenous estradiol (24). Thus, we cannot exclude the possibility that we are measuring environmental endocrine disrupting chemicals (EDCs). In animal models and in human studies, there is evidence to support a potential effect of EDCs on timing of pubertal onset and progression (32). Dichorodipehnyltichloroetane, dioxins, bisphenol A, polybrominated biphenyl, and phthalate esters have been associated with earlier puberty onset, measured as breast development, or age at menarche $(33,34)$. It has also been shown that cessation of EDCs exposure may diminish or even lead to disappearance of 
breast enlargement $(35,36)$. Unfortunately, we did not have EDCs data to confirm this hypothesis.

Our study is not exempt of limitations. We did not measure gonadotropins by a sensitive assay concurrent with the estrogen level determination. This would have allowed assessing the relation between estrogen levels, HPG and puberty onset. Also, we did not measure EDCs, thus we cannot assess their role on the associations observed. Our sample size was defined based on the primary outcome (i.e., ET) and this limits further analyses involving more complex interactions among variables. Finally, we may have had limitations imposed by the precision in our measurement of the outcome (i.e., the time between visits was 6 months, thus thelarche might be altered \pm 3 months) and also in the exposure (i.e., estrogen bioassay had a large variability), but in both cases the error would have been random and thus it will bias the result toward null. To assess misclassification in thelarche definition, we excluded from our analysis all cases that had thelarche within 7.5 and 7.9 years and controls that had thelarche within 8.0-8.5 years. We observe that both the crude and adjusted OR were stronger and statistically significant $\left(\mathrm{OR}_{\text {crude }}=2.95\right.$ (95\% CI: 1.19-7.33) and $\mathrm{OR}_{\mathrm{adj}}$ Model $1=3.46$ (95\% CI: 1.33-9.07)). However, our study also has multiple strengths that support its contribution to the field. We were able to nest a case-control study within a longitudinal cohort design, thus strengthening the assessment of our outcomes and conclusions. We followed and collected data prospectively under standardized protocols with minor attrition. A trained examiner assessed breast development every 6 months (K statistic $=0.9$ in relation to a pediatric endocrinologist), providing a reliable measurement of thelarche onset that could be confirmed in subsequent follow-ups. We were also able to collect a morning-fast blood sample during prepuberty and use an ultrasensitive RCBA to detect estrogen levels before pubertal initiation. This bioassay is considered a valid method to assess estrogen levels; the correlation coefficient between RCBA and estradiol RIA at higher levels of estrogen (>10 pg/ml) is 0.90 (22).

In conclusion, in this sample of low- to middleincome Chilean girls we found that girls who had detectable estrogen levels over $5 \mathrm{pg} / \mathrm{ml}$ during prepubertal stage had an increased risk of presenting earlier thelarche onset ( $<8$ years), even after adjusting for potential confounders such as adiposity and metabolic and hormonal markers such as DHEAS, insulin and IGF1. We postulate that possible mechanisms for this association may involve environmental EDCs; however, further studies are needed to confirm this hypothesis. Continuous follow-up of these girls will allow us to confirm the consistency of these findings using longer-term outcomes, such as peak height velocity or age at menarche.

\section{Declaration of interest}

The authors declare that there is no conflict of interest that could be perceived as prejudicing the impartiality of the research reported.

\section{Funding}

This work was supported by the Program U-INICIA VID 2011, grant U-Inicia11/18, University of Chile, the Chilean Council for Science and Technology: FONDECYT Postdoctorado 3130532 \& FONDECYT 1120326 and the World Cancer Research Fund (grant 2010/245).

\section{Acknowledgements}

We thank all the study personnel, particularly Daniela Gonzalez, for fieldwork coordination.

\section{References}

1 Sorensen K, Mouritsen A, Aksglaede L, Hagen CP, Mogensen SS \& Juul A. Recent secular trends in pubertal timing: implications for evaluation and diagnosis of precocious puberty. Hormone Research in Paediatrics 201277 137-145. (doi:10.1159/000336325)

2 Parent AS, Teilmann G, Juul A, Skakkebaek NE, Toppari J \& Bourguignon JP. The timing of normal puberty and the age limits of sexual precocity: variations around the world, secular trends, and changes after migration. Endocrine Reviews 200324 668-693. (doi:10.1210/er.2002-0019)

3 Golub MS, Collman GW, Foster PM, Kimmel CA, Rajpert-DeMeyts E, Reiter EO, Sharpe RM, Skakkebaek NE \& Toppari J. Public health implications of altered puberty timing. Pediatrics 2008121 (Suppl 3) S218-S230. (doi:10.1542/peds.2007-1813G)

4 Hoffman WH, Barbeau P, Litaker MS, Johnson MH, Howe CA \& Gutin B. Tanner staging of secondary sexual characteristics and body composition, blood pressure, and insulin in black girls. Obesity Research 200513 2195-2201. (doi:10.1038/oby.2005.272)

5 Klein KO, Mericq V, Brown-Dawson JM, Larmore KA, Cabezas P \& Cortinez A. Estrogen levels in girls with premature thelarche compared with normal prepubertal girls as determined by an ultrasensitive recombinant cell bioassay. Journal of Pediatrics 1999134 190-192. (doi:10.1016/S0022-3476(99)70414-2)

6 Shi L, Remer T, Buyken AE, Hartmann MF, Hoffmann P \& Wudy SA. Prepubertal urinary estrogen excretion and its relationship with pubertal timing. American Journal of Physiology. Endocrinology and Metabolism 2010299 E990-E997. (doi:10.1152/ajpendo.00374.2010)

7 Muti P, Quattrin T, Grant BJ, Krogh V, Micheli A, Schunemann HJ, Ram M, Freudenheim JL, Sieri S, Trevisan M \& Berrino F. Fasting glucose is a risk factor for breast cancer: a prospective study. Cancer Epidemiology, Biomarkers and Prevention 200211 1361-1368.

8 Pollak MN. Endocrine effects of IGF-I on normal and transformed breast epithelial cells: potential relevance to strategies for breast cancer treatment and prevention. Breast Cancer Research and Treatment 199847 209-217. (doi:10.1023/A:1005950916707)

9 Sales DS, Moreira AC, Camacho-Hubner C, Ricco RG, Daneluzzi JC, Campos AD \& Martinelli CE Jr. Serum insulin-like growth factor (IGF)-I and IGF-binding protein-3 in girls with premature thelarche. Journal of Pediatric Endocrinology and Metabolism 200316 827-833. (doi:10.1515/ JPEM.2003.16.6.827) 
10 Muir A. Precocious puberty. Pediatrics in Review 200627 373-381. (doi:10.1542/pir.27-10-373)

11 Dunger DB, Ahmed ML \& Ong KK. Early and late weight gain and the timing of puberty. Molecular and Cellular Endocrinology 2006 254-255 140-145. (doi:10.1016/j.mce.2006.04.003)

12 McLachlan JA, Simpson E \& Martin M. Endocrine disrupters and female reproductive health. Best Practice \& Research. Clinical Endocrinology \& Metabolism 200620 63-75. (doi:10.1016/j.beem. 2005.09.009)

13 Kaplowitz PB. Link between body fat and the timing of puberty. Pediatrics 2008121 (Suppl 3) S208-S217. (doi:10.1542/peds.20071813F)

14 Blank SK, McCartney CR, Chhabra S, Helm KD, Eagleson CA, Chang RJ $\&$ Marshall JC. Modulation of gonadotropin-releasing hormone pulse generator sensitivity to progesterone inhibition in hyperandrogenic adolescent girls - implications for regulation of pubertal maturation. Journal of Clinical Endocrinology and Metabolism 200994 2360-2366. (doi:10.1210/jc.2008-2606)

15 Poretsky L, Cataldo NA, Rosenwaks Z \& Giudice LC. The insulin-related ovarian regulatory system in health and disease. Endocrine Reviews 1999 20 535-582. (doi:10.1210/edrv.20.4.0374)

16 Burt Solorzano CM \& McCartney CR. Obesity and the pubertal transition in girls and boys. Reproduction $2010140399-410$. (doi:10.1530/REP-10-0119)

17 Sorensen K, Andersson AM, Skakkebaek NE \& Juul A. Serum sex hormone-binding globulin levels in healthy children and girls with precocious puberty before and during gonadotropin-releasing hormone agonist treatment. Journal of Clinical Endocrinology and Metabolism 200792 3189-3196. (doi:10.1210/jc.2007-0231)

18 Marshall WA \& Tanner JM. Variations in pattern of pubertal changes in girls. Archives of Disease in Childhood 196944 291-303. (doi:10.1136/ adc. 44.235.291)

19 Kain J, Corvalan C, Lera L, Galvan M \& Uauy R. Accelerated growth in early life and obesity in preschool Chilean children. Obesity 200917 1603-1608. (doi:10.1038/oby.2009.37)

20 Rosen DS. Physiologic growth and development during adolescence. Pediatrics in Review 200425 194-200. (doi:10.1542/pir.25-6-194)

21 Corvalan C, Uauy R, Stein AD, Kain J \& Martorell R. Effect of growth on cardiometabolic status at $4 \mathrm{y}$ of age. American Journal of Clinical Nutrition 200990 547-555. (doi:10.3945/ajcn.2008.27318)

22 Klein KO, Baron J, Colli MJ, McDonnell DP \& Cutler GB Jr. Estrogen levels in childhood determined by an ultrasensitive recombinant cell bioassay. Journal of Clinical Investigation 199494 2475-2480. (doi:10.1172/JCI117616)

23 Klein KO, Baron J, Barnes KM, Pescovitz OH \& Cutler GB Jr. Use of an ultrasensitive recombinant cell bioassay to determine estrogen levels in girls with precocious puberty treated with a luteinizing hormonereleasing hormone agonist. Journal of Clinical Endocrinology and Metabolism 199883 2387-2389. (doi:10.1210/jcem.83.7.4929)

24 Janfaza M, Sherman TI, Larmore KA, Brown-Dawson J \& Klein KO. Estradiol levels and secretory dynamics in normal girls and boys as determined by an ultrasensitive bioassay: a 10 year experience. Journal of Pediatric Endocrinology and Metabolism 200619 901-909. (doi:10.1515/JPEM.2006.19.7.901)
25 de Onis M, Onyango AW, Borghi E, Siyam A, Nishida C \& Siekmann J. Development of a WHO growth reference for school-aged children and adolescents. Bulletin of the World Health Organization 200785 660-667. (doi:10.2471/BLT.07.043497)

26 Fernandez JR, Redden DT, Pietrobelli A \& Allison DB. Waist circumference percentiles in nationally representative samples of African-American, European-American, and Mexican-American children and adolescents. Journal of Pediatrics 2004145 439-444. (doi:10.1016/j.jpeds.2004.06.044)

27 Greenland S, Pearl J \& Robins JM. Causal diagrams for epidemiologic research. Epidemiology 1999 10 37-48. (doi:10.1097/00001648-19990 1000-00008)

28 Crocker MK, Stern EA, Sedaka NM, Shomaker LB, Brady SM, Ali AH, Shawker TH, Hubbard VS \& Yanovski JA. Sexual dimorphisms in the associations of BMI and body fat with indices of pubertal development in girls and boys. Journal of Clinical Endocrinology and Metabolism 2014 99 E1519-E1529. (doi:10.1210/jc.2014-1384)

29 Aksglaede L, Sorensen K, Petersen JH, Skakkebaek NE \& Juul A. Recent decline in age at breast development: the Copenhagen Puberty Study. Pediatrics 2009123 e932-e939. (doi:10.1542/peds.2008-2491)

30 Corvalan C, Uauy R \& Mericq V. Obesity is positively associated with dehydroepiandrosterone sulfate concentrations at $7 \mathrm{y}$ in Chilean children of normal birth weight. American Journal of Clinical Nutrition 201397 318-325. (doi:10.3945/ajcn.112.037325)

31 Klein KO, Larmore KA, de Lancey E, Brown JM, Considine RV \& Hassink SG. Effect of obesity on estradiol level, and its relationship to leptin, bone maturation, and bone mineral density in children. Journal of Clinical Endocrinology and Metabolism 199883 3469-3475. (doi:10.1210/jcem.83.10.5204)

32 Buck Louis GM, Gray LE Jr, Marcus M, Ojeda SR, Pescovitz OH, Witchel SF, Sippell W, Abbott DH, Soto A, Tyl RW et al. Environmental factors and puberty timing: expert panel research needs. Pediatrics 2008 121 (Suppl 3) S192-S207. (doi:10.1542/peds.1813E)

33 Buttke DE, Sircar K \& Martin C. Exposures to endocrine-disrupting chemicals and age of menarche in adolescent girls in NHANES (2003-2008). Environmental Health Perspectives 2012120 1613-1618. (doi:10.1289/ehp.1104748)

34 Roy JR, Chakraborty S \& Chakraborty TR. Estrogen-like endocrine disrupting chemicals affecting puberty in humans - a review. Medical Science Monitor 200915 RA137-RA145.

35 Fenton SE, Reed C \& Newbold RR. Perinatal environmental exposures affect mammary development, function, and cancer risk in adulthood. Annual Review of Pharmacology and Toxicology 201152 455-479. (doi:10.1146/annurev-pharmtox-010611-134659)

36 Mouritsen A, Aksglaede L, Sorensen K, Mogensen SS, Leffers H, Main KM, Frederiksen H, Andersson AM, Skakkebaek NE \& Juul A. Hypothesis: exposure to endocrine-disrupting chemicals may interfere with timing of puberty. International Journal of Andrology 201033 346-359. (doi:10.1111/j.1365-2605.2010.01051.x)

37 Buggs C, Weinberg F, Kim E, Wolfe A, Radovick S \& Wondisford F. Insulin augments GnRH-stimulated LH $\beta$ gene expression by Egr-1. Molecular and Cellular Endocrinology 2006249 99-106. (doi:10.1016/ j.mce.2006.02.001)

Received 24 March 2015

Revised version received 25 August 2015

Accepted 8 September 2015 